DOI: $10.12731 / 2070-7568-2017-4-208-222$

УДК 330.14

\title{
ЭКОНОМИЧЕСКИЕ ПОДХОДЫ К ОЦЕНКЕ ЭФФЕКТИВНОСТИ ИНТЕЛЛЕКТУАЛЬНОГО КАПИТАЛА ХОЗЯЙСТВУЮЩЕГО СУБЬЕКТА
}

Устинова O.E.

Данная работа посвящена одной из актуальных проблем в практике российской экономики - исследованию экономических подходов к оиенке эффективности интеллектуального капитала. Вопросы эффективного управления в современных условиях становятся особенно актуальными и требуют подробного изучения. С этой целью в данной статье приводится анализ основных научных подходов $к$ пониманию и оценке эффективности. В рамках ресурсного подхода к оиенке эффективности управления обозначен синергетический эффект, как следствие взаимодействия и комбинации различных факторов и ресурсов, в том числе интеллектуальных, материальных, финансовых, способствующих росту основных экономических показателей хозяйствующего субъекта. Результаты исследования в дальнейшем могут быть использованы для формирования модели экономической оченки влияния интеллектуального капитала на конкурентоспособность компаний.

Ключевые слова: эффективность; интеллектуальный капитал; управление; синергизм; развитие.

\section{ECONOMIC APPROACHES \\ TO ASSESSING THE EFFECTIVENESS OF COMPANIES' INTELLECTUAL CAPITAL}

\section{Ustinova O.E.}

The issues of effective management of intellectual capital of economic entities in modern conditions become especially urgent and require de- 
tailed study. To this end, this article analyzes the main scientific approaches to understanding and evaluating effectiveness. Within the framework of the resource approach to the assessment of management effectiveness, a synergetic effect is identified, as a consequence of interaction and a combination of various factors and resources, including intellectual, material, financial, contributing to the growth of the basic economic indicators of the business entity. The results of the research in the future can be used to form a model for the economic evaluation of the influence of intellectual capital on the competitiveness of companies.

Keywords: efficiency; intellectual capital; management; synergism; development.

Социально-экономическое развитие мирового сообщества свидетельствует о наличии зависимости темпов экономического роста и уровня благосостояния населения от производственных факторов, традиционно включающих землю, труд, капитал. Бесспорно, на ранних стадиях развития капитализма они играли решающую роль, однако на современном этапе формирования мировой экономики не стоит их рассматривать как безусловные факторы развития. Повышение роли знаний во всех сферах деятельности человека, обусловленное информационной революцией, является основной характерной чертой настоящего времени. В разные экономические эпохи приоритет в производстве принадлежал различным ресурсам: от природных и трудовых в доиндустриальном обществе, материальных - в индустриальном, а интеллектуальных и информационных - в постиндустриальном. Опубликованные международные рейтинги и анализ статистический данных свидетельствуют о том, что страны с ограниченными природными ресурсами и небольшой территорией по отдельным показателям являются лидерами и занимают ведущие позиции. Так, показатель ВВП (в млрд. долларах США) за 2016 год составил $[10,11]$ : первое место США 17 947, второе КНР - 10 983, третье Япония - 4 123, четвертое Германия - 2849, Россия занимает 12-е место (1 326). Вместе с тем, по показателю ВВП на душу населения США находится на 5-м месте 
(57 220), после Люксембурга, Швейцарии, Норвегии и Катара, а Россия лишь на 66-м (7 742). Ситуация в России в условиях экономического кризиса и действующих санкций требует достаточно пристального внимания к развитию интеллектуального потенциала и обеспечению его эффективного использования. Таким образом, в сложившихся условиях ключевым источником экономического роста может стать интеллектуальный капитал, при этом его масштаб и качество в значительной и возрастающей степени будут обуславливать основные параметры инновационного развития.

Анализ официальных сведений Федеральной службы государственной статистики РФ об инновационной деятельности организаций [12] показывает, что в 2015 г. наблюдается рост доли инновационных товаров, работ, услуг в общем произведенном объеме $(8,4 \%)$. При этом в организациях сферы услуг доля инновационной составляющей выше (12,9\%) по сравнению с предприятиями промышленного производства (7,9\%). По данным Федеральной службы интеллектуальной собственности динамика объемных показателей по товарным знакам в 2016 году по отношению к 2014 г. составляет прирост 30\%. Вместе с тем, динамика объемных показателей по изобретениям и полезным моделям отрицательная (таб. 1), исключение составляют промышленные образцы [11]. Ряд исследований «констатируют, что в 2020-е годы будет существовать серьезный дефицит высококачественного человеческого капитала», что будет предопределять конкурентное положение страны в мировом экономическом обороте [2].

Динамика объемных показателей по группам объектов интеллектуальной собственности за 2014-2016 гг. [11].

В этой связи умение верно оценить состояние интеллектуального капитала, его компонентов и способность их эффективно использовать переходят в состав главнейших задач менеджмента. Настоящая работа посвящена анализу научных подходов к оценке эффективности управления интеллектуального капитала в процессах его формирования, развития, распределения и использования. 
Таблица 1.

\begin{tabular}{|l|c|c|c|c|}
\hline $\begin{array}{c}\text { Наименование групп объектов } \\
\text { интеллектуальной собственности }\end{array}$ & 2014 г. & 2015 г. & 2016 г. & 2014 г. / 2016 г. \\
\hline Товарные знаки & 42328 & 43067 & 55215 & $+30 \%$ \\
\hline $\begin{array}{l}\text { Программы для ЭВМ, базы данных и } \\
\text { топологии интегральных микросхем }\end{array}$ & 15148 & 15691 & 15858 & $+5 \%$ \\
\hline Изобретения & 33950 & 34706 & 33536 & $-1 \%$ \\
\hline Полезные модели & 13080 & 9008 & 8875 & $-32 \%$ \\
\hline Промышленные образцы & 3742 & 5459 & 4455 & $+19 \%$ \\
\hline
\end{tabular}

Современная конкурентная среда в условиях динамично развивающегося рынка обуславливает необходимость постоянного совершенствования научных подходов, методов и способов управления интеллектуальными ресурсами. Активные исследования интеллектуального капитала связаны с оценкой экономической эффективности его компонентов, в том числе человеческого, организационного и потребительского. Такие исследования необходимы потому, что эффективность является критерием принятия экономических решений [3]. Попытки провести экономический анализ нематериальных факторов предпринимались достаточно давно, при этом исследователи пытались выявить состав и структуру нематериальных элементов. Английский экономист Г. Маклеод выделил в составе капитала вещественный и невещественный, понимая под последним способности, которыми обладает человек, и определяет структурные компоненты: «личный, нравственный и умственный капитал» [7, с. 76]. С позиции капитализации, рассматривая капитал как источник получения прибыли, автор отдает преимущество умственной его составляющей. Мак-Куллох утверждал, что «инвестиции в человеческое существо индивида должны в течение предстоящей жизни принести норму дохода, согласующуюся с другими видами инвестиций плюс нормальную норму дохода, определяемую рыночной процентной ставкой» [21, с. 21]. Современный этап изучения структуры интеллектуального капитала восходит к трудам Фридмена и Кендрика. Так, в концепции совокупного капитала Дж. Кендрик поделил его на вещественный и невещественный. При этом, вещественный, автор представляет 
как интеллектуальный и подразделяет на «знания индивидуумов, накопленные ими благодаря инвестициям в образование и научные исследования» [20]. М. Фридман в составе активов организации выделил гуманитарный капитал, характеризуя его как капитал, который «довольно трудно перевести в денежную форму, так как главный источник будущего дохода о него заключен в работниках фирмы» [19, с. 14].

Энни Брукинг наряду с человеческими активами выделяет в составе капитала интеллектуальную собственность, инфрастуктурные и рыночные активы [4, с. 31]. Эдвинссон Л. и М. Мэлоун разграничивают структуру интеллектуального капитала на две составляющие: человеческий и структурный капиталы и более подробно останавливаются на последнем [13]. Иные подходы, развивающие предложенные идеи, представлены также Т. Стюартом и другими исследователями, выделившими основные три компоненты интеллектуального капитала: человеческий, структурный (организационный), клиентский (потребительский).

В последние десятилетия в научных кругах появилось достаточное большое количество авторских трудов, затрагивающих проблемы анализа и эффективного управления интеллектуальным капиталом. Среди них заслуживают внимания работы Э. Брукинг (1996), Т. Стюарта (1997), Л. Эдвинссона, М. Мэлоуна (1997), Й. Рууса (1998). Так, Л. Эдвинссон и М. Мэлоун предлагают новые методы социально-экономических измерений, сопоставляя интеллектуальный капитал с «корнями компании, скрытыми условиями развития, которых не видно за внешним фасадом» [14]. Их работа «Интеллектуальный капитал» (1997) основана на прикладных социологических исследованиях и применима в практике современных компаний. Следует заметить, что указанная концепция послужила основой для последующих разработок методик оценки относительно интеллектуального капитала общества. В 1991 году появилась Т. Стюарта книга «Сила интеллекта: как интеллектуальный капитал становиться наиболее ценным активом в Америке», в последствии подробно проанализировал это понятие в своей работе «Интел- 
лектуальный капитал - новый источник богатства организаций», опубликованной в 1997 г. В эту категорию автор включает знания, опыт, информацию, интеллектуальную собственность, участвующие в создании ценностей [18]. В работах И. Рууса и его коллег рассматриваются вопросы управления нематериальными активами фирмы - знаниями, человеческим капиталом, технологиями, клиентским отношениям и т.П., то есть тем, что становится основой конкурентных преимуществ компаний [8].

Указанные исследователи занимались проблемами разработки методов оценки интеллектуального капитала. Наряду с ними следует также отметить авторов сбалансированной системы показателей Д. Нортона, Р. Каплан [5]. В настоящее время на основе различных методов учеными предложены несколько десятков методик измерения и оценки стоимости интеллектуального капитала. В связи с разной направленностью и наличием специфики компонентов интеллектуального капитала ни одна из методик не может рассматриваться как универсальная. Более того, разработку методов измерения интеллектуального капитала осложняет то обстоятельство, что традиционные методы экономических оценок и измерений базируются на принципах бухгалтерского учета и в современных условиях не являются адекватными. Так, голландский исследователь Д. Андриссен [1] подверг критике классический бухгалтерский метод двойной записи в отношении интеллектуального капитала как противоречащую его сущности. В качестве примера приведен товарный знак в составе нематериальных активов, который в процессе эксплуатации амортизируется, передавая часть своей стоимости на вновь создаваемый продукт, уменьшая при этом свою стоимость. Вместе с тем, со временем, он не только не теряет своей ценности, но и способен ее приумножать. В этой связи активы компании целесообразно оценивать не только балансовой ее стоимостью, но и формирующими ее рыночными факторами. В дополнение к вышесказанному отметим, что некоторые компоненты интеллектуального капитала вообще не находят отражения в бухгалтерском учете, такие как, лояльность и приверженность потребителей, квалифика- 
ция персонала, каналы распределения и прочие. Однако при определении рыночной стоимости хозяйствующего субъекта следует проводить оценку с учетом влияния различных факторов, состав которых может варьироваться в зависимости от поставленных целей и профессионального мнения.

Наиболее полный обзор методов измерения стоимости нематериальных активов и интеллектуального капитала представлен на сайте Карла-Эрика Свейби [22]. Он выделяет методы и группирует их в четыре категории:

1. Методы прямого измерения интеллектуального капитала (Direct Intellectual Capital Methods, DICM), с помощью которых оценивается денежная стоимость неосязаемых активов через выделение их компонентов. Декомпозированный интеллектуальный капитал измеряется по отдельным элементам посредством агрегирующего показателя, определяющегося сложением компонентов, либо более сложным способом.

2. Методы рыночной капитализации (Market Capitalization Methods, MCM). Величина интеллектуального капитала хозяйствующего субъекта оценивается как разница между рыночной капитализацией компании и стоимостью ее собственного капитала. При этом существуют проблемы взаимоувязки балансовой и рыночной стоимости, так как их измерение осуществляется в разных единицах - «искусственных» и реальных деньгах, что вызывает затруднения при сравнивании объектов. Более того указанный метод концептуально противоречив в силу отражения стоимости как результат по свершившимся событиям по данным бухгалтерского учета. При этом рыночная стоимость показывает текущую деятельность и долгосрочные перспективы.

3. Методы определения отдачи на активы (Return on Assets methods, ROA). Рентабельность активов компании сравнивается с аналогичным отраслевым показателем. При этом, выявленная разница, умноженная на среднее значение активов хозяйствующего субъекта, показывает средний ежегодный 
доход от нематериальных активов. Оценка их стоимости, а также стоимости интеллектуального капитала может быть получена путем дисконтирования или капитализации полученного значения.

4. Методы составления систем показателей (Scorecard Methods, $\mathrm{SC})$. Разные элементы нематериальных активов или интеллектуального капитала представляются в виде взаимосвязанных систем показателей или схем и не предполагают получение его стоимостной (денежной) оценки. Указанные методы аналогичны методам диагностической информационной системы, их целесообразно использовать для задач управленческого характера.

Целесообразно в вышеуказанный список включить точные измерительные системы (Proper Measurement Sistems, MS), предполагающие деление всего, что представляет ценность в исследуемой организации или ее окружении на атрибуты, которые можно измерить. Они объединяются в измерительную систему, состоящую из иерархии совместных измерений ценности (Conjoint Value Hierarchy, $\mathrm{CVH}^{1}$ ). Для получения надежных расчетов стоимости (ценности) компании используются реальные данные, которые могут быть объединены с финансовыми данными в целях определения эффективности расходования средств и других показателей. При этом методологии MS, в случае надлежащей их реализации, позволяют не только надежно измерить, но и адекватно комбинировать интеллектуальные и финансовые ресурсы посредством беспристрастной оценки всех ресурсов компании.

В целях оценки стоимости отдельных компонентов интеллектуального капитала известны и используются три альтернативных подхода [6]:

${ }^{1}$ Суть метода совместных измерений (conjoint measurement) состоит в декомпозиции целостного суждения о ценности объекта измерения (порядковая шкала) на удельные ценности атрибутов объекта (интервальная шкала). Экономическими и маркетинговыми исследованиями этого метода занимались Дэниел МакФадден и Дэниел Канеман, получившие Нобелевские премии в 2000 и 2002 гг. соответственно. 
- рыночный, опирающийся на владении рыночной информации об аналогичных объектах интеллектуального капитала, основным его недостатком считается ограничения в ее доступе;

- затратный, заключающийся в расчете расходов, необходимых для воспроизводства объектов интеллектуального капитала, а также связанные с их созданием, тестированием, патентованием;

- доходный метод, базирующийся на измерении способности интеллектуального капитала приносить доход. Он также требует точной рыночной информации о перспективах актива, в котором используется оцениваемый объект. Каждый из перечисленных подходов имеет различные методы оценки и зависит от конкретного объекта.

Среди подходов, связанных с оценкой эффективности управления, следует выделить:

- целевой, оценивающий степень достижения при реализации обозначенных целей;

- ресурсный, связанный с получением нужного максимального результата при минимальных затратах;

- оценка состояния самого хозяйствующего субъекта, подразумевающая изучение динамики основных экономических показателей и их сопоставления с другими значениями;

- комплексный подход - в той или иной степени сочетающий в себе все вышеперечисленные.

Учитывая многообразие видов управления целесообразно обозначить критерии, в соответствии с которыми эффективность менеджмента будет возрастать (рис. 1). Прокомментируем некоторые из них. В зависимости от средств воздействия на компоненты интеллектуального капитала эффективность их управления может рассматриваться с позиции стратегического значения, ориентированного на долгосрочную перспективу развития хозяйствующего субъекта и, напротив, тактического, нацеленного на решение текущих задач. Мотивационная и стимулирующая эффективность в большей степени может быть использована в отношении человече- 
ского капитала. По уровню проявления эффективность управления интеллектуальными ресурсами может иметь народно-хозяйственное, региональное, отраслевое и внутрикорпоративное значение.

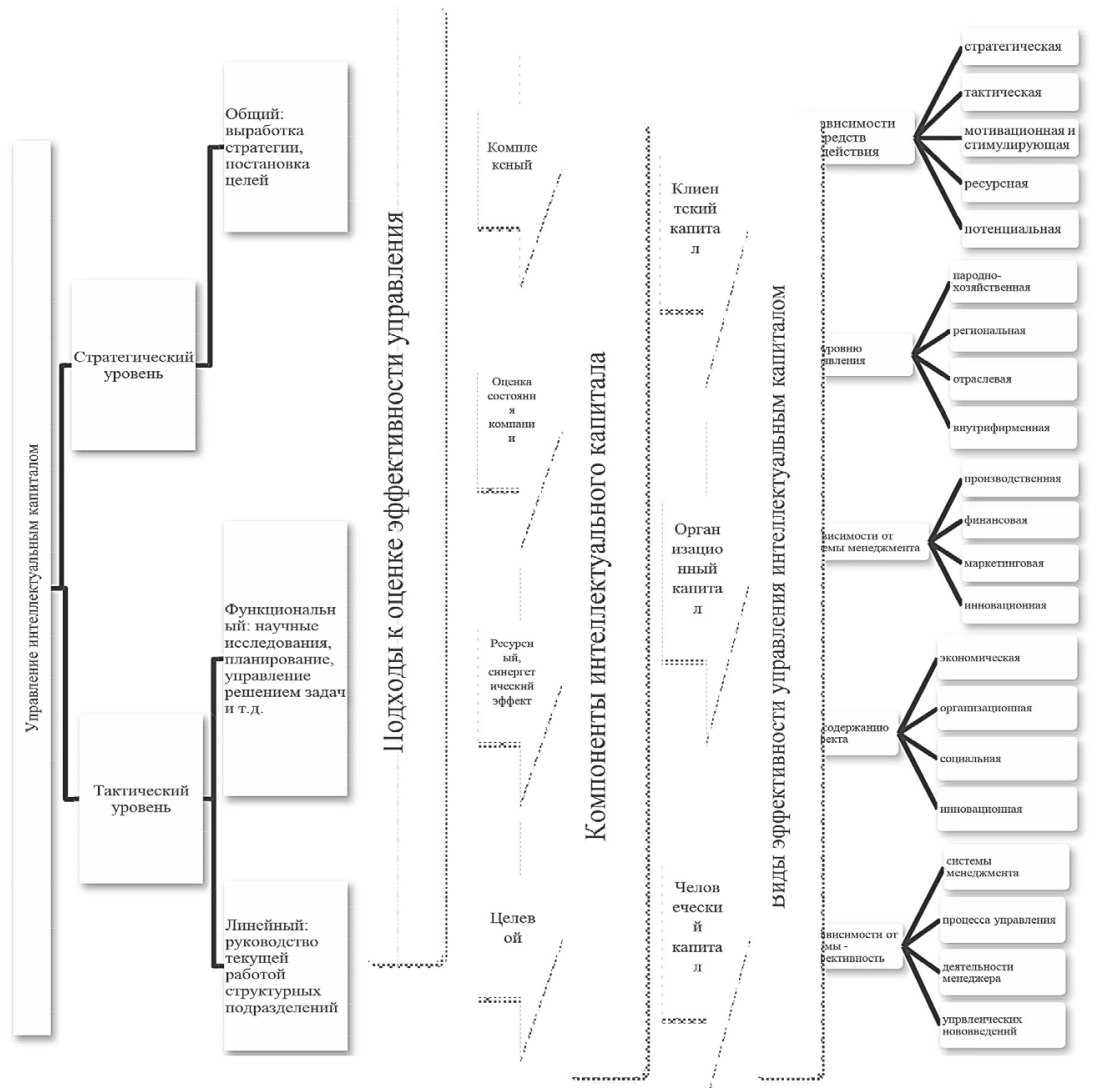

Рис. 1. Классификация видов эффективности управления компонентами интеллектуального капитала

Среди изучаемых систем менеджмента наибольший интерес, с точки зрения управления интеллектуальным капиталом, вызывает инновационная эффективность, поскольку в современных условиях она становится «драйвером» развития экономики. Более того, по содержанию самого эффекта имеет смысл выделить его экономическую, 
организационную, социальную и инновационную составляющую. В это связи не стоит забывать о роли государства как регулятора общественных отношений в сфере интеллектуальной собственности и инновационного развития общества. В зависимости от формы управления эффективность может оцениваться в отношении определенной системы менеджмента, непосредственно процесса управления либо деятельности самого менеджера. При этом следует обратить внимание на эффективность управленческих нововведений.

В рамках ресурсного подхода особый интерес вызывает синергетический эффект. Он возникает и проявляется в результате взаимодействия объектов интеллектуального капитала и других видов ресурсов хозяйствующего субъекта. Особого внимания заслуживает концепция синергизма, одним из ярких представителей которой является Х. Итами. Автор в своей работе «Мобилизация невидимых активов» [16] первым обозначил проблему важности неосязаемых активов. Автором предлагается синергизм как «процесс роста эффективности использования ресурсов», при этом выделяются физические (материальные) активы и невидимые (нематериальные). Невидимые активы хозяйствующих субъектов выступают в качестве потенциала получения будущей прибыли, более того, они, как правило, не отражены в составе бухгалтерской (финансовой) отчетности, например, знания и опыт, репутация, лояльность клиентов и др. Вместе с тем Х. Итами придает особую важность этим активам, поскольку их взаимодействие и комбинация с другими ресурсами, а также их развитие и применение в других сферах деятельности хозяйствующего субъекта способны обеспечить рост компании. Автором справедливо подчеркнута уникальность невидимых активов и их долгосрочный потенциал как источников создания конкурентных преимуществ.

В современной деловой практике синергизм рассматривается как совместное, взаимозависимое и взаимодополняющее действие двух или более факторов в определенном направлении. При этом эффект синергии может иметь как положительное, так и отрицательное значение, к примеру, при использовании новейших тех- 
нологий на базе устаревшего оборудования. В этой связи одной из ключевых задач управления интеллектуальным капиталом организации на всех его уровнях, как на корпоративном, так и на функциональном, заключается в том, чтобы создать благоприятные условия для появления его положительного эффекта.

Анализ научных подходов к изучению эффективности управления интеллектуальным капиталом позволили сформулировать ее как положительный результат процессов воздействия субъектами на ресурсы организации, их дальнейшее синергетическое взаимодействие, способствующее росту конкурентоспособности и максимизации ценности хозяйствующего субъекта. Анализ научных источников по теме исследования показывает, что исчерпывающего представления об оценки эффективности интеллектуального капитала еще не сформировано. В этой связи остается не решенной актуальная проблема современной организации в части оценки влияния интеллектуального капитала на ее конкурентоспособность. Изучение структуры компонентов интеллектуального капитала и оценки влияния каждого из них на конкурентоспособность хозяйствующих субъектов позволит решать задачи дальнейшего повышения эффективности их деятельности.

\section{Список литературы}

1. Андриссен Д. Невесомое богатство. Определите стоимость вашей компании в экономике нематериальных активов / Д. Андриссен, Р. Тиссен. М.: Олимп-Бизнес, 2004. 304 с.

2. Аузан А.А. О возможности перехода к экономической стратегии, основанной на специфике человеческого капитала в России // Журнал НЭА. 2015. № 2 (26). С. 243-248.

3. Богатырева С.В., Титов А.Б., Куприянова М.Ю. Экономическая эффективность как основа формирования управленческих решений // Экономика и менеджмент систем управления. 2016. Т. 20. № 2.1. С. 116-122.

4. Брукинг Э. Интеллектуальный капитал: ключ к успеху в новом тысячелетии: пер. с англ.; под ред. Л.Н. Ковачина. СПб.: Питер, 2001. 288 с.

5. Каплан Р.С., Нортон Д.П. Сбалансированная система показателей. От стратегии к действию / пер. с анг. М.: Олимп-Бизнес, 2006. 320 с. 
6. Козырев А.Н., Макаров В.Л. Оценка стоимости нематериальных активов и интеллектуальной собственности. М.: РИЦ ГШ ВС РФ, 2003. 368 с.

7. Маклеод Г. Основания политической экономии. Пер.: Веселовский М.П. СПб.: Н. Тиблен, 1865. 706 с.

8. Руус Й., Пайк С. Интеллектуальный капитал: практика управления / Й. Руус, С. Пайк, Фернстрем Л. СПб.: ВШ Менеджмента, 2010. 436 с.

9. Сайт Министерства экономического развития. Россия в международных рейтингах. [Электронный ресурс]. http://economy.gov.ru/ minec/activity/sections/bizinmprove/rankings

10. Сайт Известия. [Электронный ресурc]. https://iz.ru/news/675077Сайт Федеральной службы интеллектуальной собственности (РОСПАТЕНТ). [Электронный pecypc]. http://www.rupto.ru/about/stat/otchet_rp_2016.pdf

11. Сайт Федеральной службы интеллектуальной собственности (РОСПАТЕНТ). [ЭЛ. p.]. http://www.rupto.ru/about/stat/otchet_rp_2016.pdf

12. Сайт Федеральной службы государственной статистики РФ. [Электронный ресурc]. http://www.gks.ru/wps/wcm/connect/rosstat_main/ rosstat/ru/statistics/science_and_innovations/science/\#

13. Эдвинссон Л. Корпоративная долгота. Навигация в экономике, основанной на знаниях. М.: ИНФРА-М, 2005. 252 с.

14. Эдвинссон Л. Корпоративная долгота. Навигация в экономике, основанной на знаниях. М.: ИНФРА-М, 2005. 252 с.

15. Becker G. Human Capital. N.Y.: Columbia University Press. 1964.

16. Itami H. Mobilizing invisible assets. London Harvard University Press. 1991. P. 186.

17. Feiwel G.R. The Intellectual Capital of Michal Kalecki. University of Tennessee Press, 1975.

18. Stewart T.A. Intellectual Capital: The New Wealth of Organizations. N.Y.-L.: Doubleday / Currency, 1997.

19. Friedman M. The Basic Postulates of the Demand Theory // Economic Studies Quarterly. 1963. Vol. 14

20.Kendrick J.W. Productivity Trends: Capital and Labour // Review of Economics and Statistics. 1956. May

21. Mc Cullox J.R. The principles of Plitical Economy / J.R. Mc Cullox, Alex Murrey@Son, 1870. P. 66.

22. Sveiby K. Methods for Measuring Intangible Assets. htpp://www.sveiby.com 


\section{References}

1. Andrissen D., Tissen R. Nevesomoe bogatstvo. Opredelite stoimost' vashey kompanii $v$ ekonomike nematerial'nykh aktivov [Weightless Wealth. Determine the value of your company in the economy of intangible assets]. M.: Olimp-Biznes, 2004. 304 p.

2. Auzan A.A. Zhurnal NEA. 2015. № 2 (26), pp. 243-248.

3. Bogatyreva S.V., Titov A.B., Kupriyanova M.Yu. Ekonomika i menedzhment sistem upravleniya. 2016. V. 20. № 2.1, pp. 116-122.

4. Bruking E. Intellektual'nyy kapital: klyuch k uspekhu v novom tysyacheletii [Intellectual capital: the key to success in the new millennium]; ed. L.N. Kovachin. SPb.: Piter, 2001. 288 p.

5. Kaplan R.S., Norton D.P. Sbalansirovannaya sistema pokazateley. Ot strategii $k$ deystviyu [Balanced scorecard. From strategy to action] / per. s ang. M.: Olimp-Biznes, 2006. 320 p.

6. Kozyrev A.N., Makarov V.L. Otsenka stoimosti nematerial'nykh aktivov $i$ intellektual'noy sobstvennost $i$ [Valuation of intangible assets and intellectual property]. M.: RITs GSh VS RF, 2003. 368 p.

7. Makleod G. Osnovaniya politicheskoy ekonomii [Foundations of political economy]. Per.: Veselovskiy M.P. SPb.: N. Tiblen, 1865. 706 p.

8. Ruus Y., Payk S., Fernstrem L. Intellektual'nyy kapital: praktika upravleniya [Intellectual Capital: Practice of Management]. SPb.: Vysshaya Shkola Menedzhmenta, 2010. 436 p.

9. Sayt Ministerstva ekonomicheskogo razvitiya. Rossiya v mezhdunarodnykh reytingakh [The site of the Ministry of Economic Development. Russia in international ratings]. http://economy.gov.ru/minec/activity/ sections/bizinmprove/rankings

10. Sayt Izvestiya [The site of Izvestia]. https://iz.ru/news/675077

11. ROSPATENT. http://www.rupto.ru/about/stat/otchet_rp_2016.pdf

12. Sayt Federal'noy sluzhby gosudarstvennoy statistiki $R F$ [The site of the Federal Service of State Statistics of the Russian Federation]. http:// www.gks.ru/wps/wcm/connect/rosstat_main/rosstat/ru/statistics/science and innovations/science/\#

13. Edvinsson L., Meloun M. Intellektual'nyy kapital. Opredelenie istinnoy stoimosti kompanii [Intellectual Capital. Determining the true value of 
the company]; ed. V.L. Inozemtsev. Novaya postindustrial'naya volna na Zapade: antologiya [New post-industrial wave in the West: an anthology]. M.: Academia, 1999, pp. 429-447, 429 p.

14. Edvinsson L. Korporativnaya dolgota. Navigatsiya v ekonomike, osnovannoy na znaniyakh [Corporate Longitude. Navigation in an economy based on knowledge]. M.: INFRA-M, 2005. 252 p.

15. Becker G. Human Capital. N.Y.: Columbia University Press. 1964.

16. Itami H. Mobilizing invisible assets. London Harvard University Press. 1991. P. 186.

17. Feiwel G.R. The Intellectual Capital of Michal Kalecki. University of Tennessee Press, 1975.

18. Stewart T.A. Intellectual Capital: The New Wealth of Organizations. N.Y.-L.: Doubleday / Currency, 1997.

19. Friedman M. The Basic Postulates of the Demand Theory. Economic Studies Quarterly. 1963. Vol. 14

20. Kendrick J.W. Productivity Trends: Capital and Labour. Review of Economics and Statistics. 1956. May

21. Mc Cullox J.R. The principles of Plitical Economy / J.R. Mc Cullox, Alex Murrey@Son, 1870. P. 66.

22. Sveiby K. Methods for Measuring Intangible Assets. htpp://www.sveiby.com

ДАННЫЕ ОБ АВТОРЕ

Устинова Ольга Евгеньевна, кандидат экономических наук, доцент ФГКОУ ВО «Московская академия Следственного комитета Российской Федерации»

ул. Врубеля, 12, г. Москва, 125080, Российская Федерация olga.e.ustinova@yandex.ru

\section{DATA ABOUT THE AUTHOR}

Ustinova Olga Evgenievna, Candidate of Economic Sciences, Associate Professor

Moscow Academy of the Investigative Committee of the Russian Federation

12, Vrubel Str., Moscow, 125080, Russian Federation

olga.e.ustinova@yandex.ru 